\title{
An Impulse of Human Activities to Carbon Dioxide Gas Emissions in the Sub-Saharan Africa Region
}

\author{
Jean Baptiste Aboyitungiye* Suryanto Evi Gravitiani \\ Faculty of Economics \&Business, Economic Studies and Development, Sebelas Maret University, \\ J1 Ir. Sutami 36 A Surakarta Jawa Tengah, Indonesia
}

\begin{abstract}
It is complicated to determine with exactitude the share of responsibility of the various sources of pollution for Africa. This intricacy emphasizes that pollution is not always considered a major risk for the continent. The existing data are still too few and often too imprecise to assess the extent of pollution on the continent. Sub-Saharan Africa is challenged by increasing pollution reinforced by a lack of politics and goodwill to formulate and implement good practices to deal with climate change issues. This paper highlight trends in carbon emissions due to agricultural land, energy use, agriculture-forestry and fisheries (value adds), real gross domestic product, and industry and construction based on their importance to the productive capacity of SSA. The output from the proposed study of causality between variables using the impulse response functions and the forecast error decomposition revealed this: the rise in agriculture/forestry, and fisheries, and energy use has positive shocks on $\mathrm{CO}_{2}$ emissions. The carbon emissions growth in the SSA does not necessarily reckon on agricultural land, industry construction or manufactural construction, and real gross domestic product.
\end{abstract}

Keywords: Pollution, atmospheric pollutants, $\mathrm{CO}_{2}$ emissions, climate change, policy

DOI: $10.7176 / J E S D / 12-6-04$

Publication date:March $31^{\text {st }} 2021$

\section{Introduction}

Climate change and its effects now seem to be proven and linked, at least in part, to the additional anthropogenic greenhouse effect, which is reflected in the inclusion of this major issue on global political agendas(Levine and Kline 2017). The natural greenhouse effect that makes the Earth home has been modified by human activities [Solomon et al.(2007)and Society(2021)]. These activities emit greenhouse gases (GHGs) and change the atmosphere's quality (Mikhaylov et al. 2020). GHGs and atmospheric pollutants are today the main emitters and have an identical source (transport, housing, industry, and agriculture)(Eurostat 2015). There is evidence that burning fossil fuel leads to the increase of carbon dioxide and other harmful gases in the atmosphere(NAS 2021)and (Manisalidis et al.2020). Observed across the planet, carbon dioxide $\left(\mathrm{CO}_{2}\right)$ is the main representative of GHGs emissions that come from human activities during combustions of fossil resources such as petroleum, natural gas, or coal for heating and transport(Abeydeera, Mesthrige, and Samarasinghalage 2019). The issue of atmosphere degradation relates to the redefinition of methods of access to resources, of risk sharing, of the ability to integrate the environmental issue for groups operating in multiple environments (natural, social, institutional, political, administrative, expertise), interacting and evolving (Hummels and Argyrou 2021). The main propeller of global change is the increase in human needs (Bush et al. 2018). As a result of this global change made possible by the growing human population's demand, we now suffer from ozone depletion, climate change, widespread species extinction, air and water pollution, desertification, and other large-scale shifts (Wickham et al. 2019).

Besides being affected by climatic change, sub-Saharan Africa remains one of the most susceptible regions to climate disasters due to its low adaptive capability (Serdeczny et al. 2017). The recent study of Nangombe et al. (2019)demonstrated that earth temperatures in Africa will rise faster and the continent will know extreme heat in the more arid regions. The lack of policy structuration, as well as the need to integrate new criteria, are major drawbacks in dealing with the climate problem in the region (Omisore 2018). The region now finds itself afflicted by the consequences of inappropriate policies, as well as by almost endemic political instability, an inability to manage its economies effectively, and an increasingly hostile external economic milieu(Shishaye 2017). As simple survival has become more problematic, it has become increasingly difficult to avoid overexploiting natural resources and degrading the environment.

More often than not, poverty contributes to environmental degradation (Masron and Subramaniam 2019), the poor deplete the natural resources on which economic development depends. Due to a lack of sufficient resources and improper knowledge, people overuse every free resource available(Miller et al. 2021). They cannot cover the additional short-term expenses necessary to adopt environmentally sustainable development practices. To access energy, Sub-Saharan Africa is the world's poorest in the electricity region(Blimpo and Cosgrove-Davies 2019). The primary source of energy in the region is solid biomass like fuelwood and charcoal which accounts for more than 75 percent of the total energy consumed in the region (Bär et al. 2021).

Among causes of environmental issues, it is furtherly clear that our energy consumption has a detrimental impact on the environment and our health(Xing et al. 2019). Sub Saharan Africa is certainly the most contrasted 
continent with a very dichotomy of energy systems (Ganda and Ngwakwe 2014). Inefficient traditional forms of energy, mainly fuelwood and charcoal, continue to dominate in most countries of sub-Saharan Africa, especially for cooking uses(Manfred Hafner, Simone Tagliapietra, and Lucia De Strasser 2018). The impacts are diverse, concern human health, ecosystems, buildings, plant crops, landscapes, and climate change, and vary according to the different energy sources(Frantál, Pasqualetti and van Der Horst 2014).

Agricultural sub -Saharan African takes place in savanna and forest areas which support most of the continent's cropland and pasture(Larmie 2019). Future changes in land exploitation could have an impact on these symbolic landscapes. Palmer et al. (2019)demonstrated that Africa's tropical land releases $\mathrm{CO}_{2}$ emissions. This is because the land surface is covered by tropical forests and peatlands, environments that typically absorb huge amounts of $\mathrm{CO}_{2}$ from the atmosphere(Leng, Ahmed, and Jalloh 2019). African greenhouse gas emissions produced on the continent contribute to the modification of the regional climate(Niang et al.2015). Some African countries are already committed to a growth model that is resilient to climate change, but this path promises to be difficult due to a lack of resources. The challenge is therefore how to ensure economic and technical progress with the current pace while simultaneously taking into account two aspects: socio-economic and environmental. This question is crucial because of the lack of awareness leading to a bad understanding of the action programs and bad practices. The success of environmental policies throughout the world and particularly in developing regions such as sub-Saharan Africa requires awareness combined with the participation of those who are concerned(Howes et al. 2007). Five keys considered as drivers of pollution in SSA are reviewed in detail in this study: agricultural land, energy use, agriculture-forestry and fisheries (value adds), real gross domestic product, and industry-construction based on their importance to the productive capacity of SSA and their contribution to current and future GHG emissions.

Far through literature review, a series of empirical studies have been carried out to illustrate the relationship between human activities and $\mathrm{CO}_{2}$ emissions. These studies do not use the same approaches. They are based on the EKC (Environmental Kuznets Curve) hypothesis, and the gravity model for some, and the STIRPAT (Stochastic Impacts by Regression on Population, Affluence, and Technology) approach for others. Scholars have also extended it beyond income levels \& the environment and focus on $\mathrm{CO}_{2}$ emissions impacts. For example, (Ameyaw and Yao 2018)examine the relationship between the real gross domestic product (RGDP) and $\mathrm{CO}_{2}$ emissions in West African countries within the period of 2007-2014 based on a panel data model. The output from the analysis revealed a unidirectional causality running from GDP to $\mathrm{CO}_{2}$ emissions. In the same context, studies have been recorded an impact of agriculture, manufacturing industry, and service sector's value-added in the GDP on the $\mathrm{CO}_{2}$ emissions(IPCC, 2015).

Using an EKC in selected south Asian countries, Alam(2015) has found that a value adds of agriculture in the GDP has a negative significant impact on $\mathrm{CO}_{2}$ emissions where industrial and services value-added in the GDP has a great significant impact on $\mathrm{CO}_{2}$ emissions. Pant (2009) reviewed the literature on both aspects and test empirically what causes emissions of carbon dioxide to the atmosphere. Multiple linear regression analysis revealed that agricultural land, irrigation, forest area, biomass energy, and energy use lead to the increase of Carbon dioxide emission (Zhang et al. 2020). However, using an autoregressive distributed lag (ARDL) approach and Granger causality tests, Mehdi and Mounir (2017) investigate the dynamic causal links between carbon dioxide $\left(\mathrm{CO}_{2}\right)$ emissions, real Gross Domestic Product (RGDP), combustible renewables and waste consumption, maritime, and rail transport in Tunisia spanning the period 1980-2011. The empirical results suggest a bidirectional shortrun causality between $\mathrm{CO} 2$ emissions and maritime transport, and a unidirectional causality running from real GDP, combustible renewables, waste consumption, and rail transport to $\mathrm{CO}_{2}$ emissions. Sarkodie and Owusu (2017) estimated a relationship between carbon dioxide, crop, and livestock production index in Ghana. Estimating the long-run elasticities and variance decomposition by employing a time series data spanning from 1960-2013 using both fit regression and ARDL models. The study evidence has shown a bidirectional causality between crop production index and carbon dioxide emissions, and a unidirectional causality exists from livestock production index to carbon dioxide emissions. The variance decomposition has shown that future fluctuations in carbon dioxide emissions are due to shocks in the crop production index.

Scientists such as Zhao et al. (2018) and Sperry et al. (2019) believe that current developments will lead to increased extreme events (high magnitude storms and cyclones, catastrophic floods, or multi-year drought), as well as an increase in annual average temperatures over large areas of the globe. The primary cause of global warming would be the emission of increasing amounts of carbon dioxide in the atmosphere associated with the large-scale use of fossil fuels (coal, oil, natural gas). Carbon dioxide $\left(\mathrm{CO}_{2}\right)$ emissions linked to the use of energy have been stabilized in the world in 2019 IEA(2019). It is the result of the development of renewable energies in developed economies.

An extended Kaya identity and the Logarithm Mean Divisia Index (LMDI I) have been applied by Engo (2019) to identify, quantify, and explain the main driver of $\mathrm{CO}_{2}$ emissions in Cameroon from 2007 to 2014. Regarding contributions to the increase of $\mathrm{CO}_{2}$ emissions, findings have shown that population is the most positive whereas energy intensity, the substitution of fossil fuels, and penetration of renewable energies have contributed 
to the $\mathrm{CO}_{2}$ emission reduction. Yorganc (2018) employed an IPAT model as a framework using the Vector Error Correction Model (VECM). The results indicated the long-run responsiveness of $\mathrm{CO}_{2}$ emissions for the population is positive and significant. Max William Ssali (2018) conducted a unit root test, co-integration test, VECM, and FMOLS to assess the impact of economic growth, energy consumption, and population growth on carbon emissions. The output revealed that an increase in energy consumption and population growth would cause an increase in $\mathrm{CO}_{2}$ concentration.

Though in general, there are a lot of studies for Africa related to energy consumption, not much of them have been focused on the sub-Sahara African $\mathrm{CO}_{2}$ emissions. Again, causes of $\mathrm{CO}_{2}$ have been investigated in their aggregated form focusing primarily on causality analysis without exploring its dynamic impacts.

\section{Material and methodology approach}

\subsection{Econometric method}

This research is a type of descriptive analysis research with a quantitative approach. It is a time-series data type and consists of Sub -Saharan Africa region. We have chosen the best explanatory variables covering the period 1981-2014, which are directly correlated with the CO2 emissions under the constraint of the availability of data from various reviews available on the British Petroleum Council and World Bank.

$C O_{2}=\beta_{0}+\beta_{1} A L_{i t}+\beta_{2} E U_{i t}+\beta_{3} A G R I F_{i t}+\beta_{4} G D P C_{i t}+\beta_{5} I N D C O_{i t}+\varepsilon_{t}$

Where:

$\mathrm{CO}_{2}: \quad$ Carbon dioxide(kt)

AL: $\quad$ Agricultural land

$E U: \quad$ Energy use

AGRIF : $\quad$ Agriculture-forestry and fisheries (value adds)

GDPC: $\quad$ (Real)Gross domestic product

INDCO: $\quad$ Industry/construction (value adds)

$\varepsilon: \quad$ Error term

\subsection{Econometric approach}

The non-stationarity of several macroeconomic and financial series represents a problem for the application of the usual econometric methods. For the study of the evolution of these long-term series, we use the theory of cointegration which allows studying them whose linear combination is stationary. The study makes it possible to specify long-term stable relationships while jointly analyzing the short-term dynamics of the variables considered. The interest of this theory is that it provides a method of analyzing the non-stationary time series while avoiding the problem of spurious regressions ((Wang and Hafner, 2018). Analysis of these time series is primarily concerned with examining their stationary character.

There are two types of stationarity:

- A Strict Sense Stationary (SSS) process:

We say that the process $X_{t} t \in \tau$ is stationary in the strict sense (SSS), if for all $\left\{t_{1}, t_{2}, \ldots, t_{n}\right\}$ the probability distribution of $\left\{X_{t 1}, X_{t 2}, \ldots, X_{t n}\right\}$ is the same as that for $\left\{X_{t_{1+k}}, X_{t_{2+k}}, \ldots, X_{t_{n+k}}\right\} \mathrm{K}>=0$. We denote by $\left(X_{t}, t \in \tau\right) \sim S S S$ where $\tau$ is the set of indices. It should be noted that the conditions of stationarity generally retained are those of second-order stationarity (or weak or in the broad sense or asymptotic or covariance stationarity).

- $\quad$ Second-order stationarity (weak stationarity):

The process $\left(X_{t}, t \in \tau\right)$ is stationary of second-order (SL) if:

$>E\left(X_{t}^{2}\right)<\infty \forall t \in \tau$ : moments of order 2 are finite,

$>E\left(X_{t}\right)=\mu \forall t \in \tau$ : the mean of the process is constant which reflects the stability of its behavior over time,

$>\operatorname{Cov}\left(X_{t}, X_{t+h}=\gamma \forall t \in \tau, \forall h \in \tau\right.$ : the covariance between 2 periods $t$ and $t+h$ is only a function of the time difference $h$.

If at least one of its first two moments varies with time, the time series is then said to be non-stationary.

Economists focus their attention on a single equation representing for example a global consumption function, an equation teaches that these equations belong to a system or a subset of interdependent equations of which each equation makes it possible to give causal interpretations. This system is used to make simultaneous forecasts on a set of related variables. But, in a system of simultaneous equations containing one or more equations, it is not possible to obtain numerical values of each parameter in each equation because the equations are indistinguishable on the plane of the observation or they are gathered together too much we speak here of an identification problem. To do this, Sims (1980) proposed the VAR models [see Hanck et al.(2018)] as an alternative to traditional structural models with several equations. If there is real simultaneity between a series of variables, they should all be treated on an equal footing and there should be no distinction a priori between endogenous and exogenous variables. 
Modern Econometrics uses methods to establish the relational model among economic variables in a nonstructural way: the vector autoregressive model (VAR) and vector error correction model (VEC). Assuming $Y_{t}=\left(y_{1 t}, y_{2 t}, \ldots, y_{k t}\right)^{\prime}$ as k-dimensional stochastic time series, $t=1,2, \ldots T$ and $Y_{t} \sim \mathrm{I}(1)$, each $y_{i t} \sim$ $\mathrm{I}(1), \mathrm{i}=1,2, \ldots$ is affected by exogenous time series of d-dimension $X_{t}=\left(x_{1 t}, x_{2 t}, \ldots, x_{d t}\right)^{\prime}$; the VAR model can be formulated as below:

$Y_{t}=A_{1} y_{t-1}+A_{2} y_{t-1}+\cdots+A_{p} y_{t-p}+B_{t}+u_{t}$

$t=1,2, \ldots T$. If $Y_{t}$ is not affected by exogenous time series of $\mathrm{d}$ dimension $X_{t}=\left(x_{1 t}, x_{2 t}, \ldots, x_{d t}\right)^{\prime}$; VAR model of equation (2) becomes:

$Y_{t}=A_{1} y_{t-1}+A_{2} y_{t-1}+\cdots+A_{p} y_{t-p}+u_{t}$

$t=1,2, \ldots T$

From the specification above, it is interested to study the causality and analyze the effect of a shock of one of the variables considered on the others through the impulse response functions and the decomposition of the variance of the forecast error.

To study the existence of a cointegrating relationship, two approaches are often used: the method of Engle and Granger (1987) and the maximum likelihood method (Johansen $(1988,1991)$ ). Those approaches make it possible to determine the number of long-run equilibrium relationships between integrated variables of the same order regardless of the standardization used. Johansen represented a vector $X_{t}$ containing $N$ variables all $I(1)$ as a $\operatorname{VAR}(\mathrm{p})$ model.

$$
X_{t}=\emptyset_{1} X_{t-1}+, \ldots \emptyset_{p} X_{t-p}+\varepsilon_{t}
$$

Where $\varepsilon_{t} \sim B B(0, \Omega)$ and $\emptyset_{i}=(i=1, \ldots, p)$ are matrixes of parameters of size $(N \times N)$. We start first by estimating the parameters constrained by the cointegration hypothesis. We rewrite Equation (9) in the form of an error correction model:

$$
\begin{aligned}
& \Delta X_{t}=\pi_{1} \Delta X_{t-1}+, \ldots, \pi_{p-1} \Delta X_{t-p+1}+\pi_{p} X_{t-p}+\varepsilon_{t} \\
& \text { With: } \pi_{i}=-I+\emptyset_{1}+\emptyset_{2}+, \ldots, \emptyset_{i} \text { for } i=1, \ldots, p .
\end{aligned}
$$

The matrices $\pi_{i}(i=1, \ldots, p)$ have $(N \times N)$ size. All terms of this model are $I(0)$ except $X_{t-p}$ which is $I(1)$. There is therefore an imbalance between the order of integration of the left limb and the terms of the right limb. For both members to be $I(0)$ a necessary condition is that $\pi_{p} X_{t-p}$ become $I(0)$. We set $\pi_{p}=-\beta \dot{\alpha}$ where $\alpha$ a matrix $(r, N)$ that contains the $r$ cointegrating vectors and $\beta$ a matrix $(N, r)$ that contains the weights associated with each cointegrating vector.

Equation (4) is rewritten:

$X_{t}=\pi_{1} \Delta X_{t-1}+, \ldots,+\pi_{p-1} \Delta X_{t-p+1}-\beta \alpha X_{t-p}+\varepsilon_{t} \quad(6)$

To estimate the different matrices, Johansen $(1988,1989)$ proposes to use the maximum likelihood method. Under the assumption of normality of $\varepsilon_{t}$, the log-likelihood is written:

$\log L\left(\beta, \alpha, \pi_{1}, \ldots, \pi_{p-1}, \Omega\right)=-\frac{N T}{2} \log 2 \pi-\frac{T}{2} \log [(\operatorname{det} \Omega)]-\frac{1}{2} \sum_{t=1}^{T} \dot{\varepsilon}_{t} \Omega^{-1} \varepsilon_{t}$

Where $T$ is the number of observations, $N$ is the number of variables contained in $X$ and $\operatorname{det} \Omega$ denotes the determinant of the variance-covariance matrix of $\varepsilon_{t}$.

We concentrate on the log-likelihood concerning the parameters $\pi_{1}, \pi_{2}, \ldots, \pi_{p-1}$. This amount to performing the regression of $e_{o t}$ on $e_{p t}$. These are the residuals estimated by the OLS of the relations:

$\left\{\begin{array}{l}\Delta X_{t}=\theta_{01} \Delta X_{t-1}+, \ldots,+\theta_{0 p-1} \Delta_{t-p+1}+e_{o t} \\ X_{t-1}=\theta_{11} \Delta X_{t-1}+, \ldots,+\theta_{1 p-1} \Delta_{t-p+1}+e_{p t}\end{array} \forall i=1, \ldots, p-1\right.$

With: $\theta_{0 i}=\left(\pi_{i}-\beta \alpha \pi_{l}\right)$ and $\theta_{1 i}=\pi_{i}$

Using equation (4) again, it comes:

$X_{t}+\beta \dot{\alpha} X_{t-p}=\pi_{1} \Delta X_{t-1}+, \ldots,+\pi_{p-1} \Delta X_{t-p+1}+\varepsilon_{t}$

$X_{t}+\beta \dot{\alpha} X_{t-p}=\pi_{1} \Delta X_{t-1}+, \ldots,+\pi_{p-1} \Delta X_{t-p+1}+\beta \dot{\alpha}\left[\pi_{1} \Delta X_{t-1}+, \ldots,+\pi_{p-1} \Delta X_{t-p+1}\right]-$

$$
\beta \dot{\alpha}\left[\pi_{1} \Delta X_{t-1}+, \ldots,+\pi_{p-1} \Delta X_{t-p+1}\right]+\varepsilon_{t}
$$

The maximum likelihood estimators of the parameters $\left(\pi_{1}, \ldots, \pi_{p-1}\right)$ and $\beta$ are provided from the OLS applied to equation (10) having previously replaced $\alpha$ by its estimator $\hat{\alpha}$.

The estimators of $\beta$ and $\Omega$ are:

$$
\left\{\begin{array}{c}
\hat{\beta}=-S_{p o} \hat{\alpha}\left(\hat{\alpha}^{\prime S_{P P} \widehat{\alpha}}\right)^{-1}=-S_{p o} \hat{\alpha} \\
\widehat{\Omega}=S_{o o}-S_{o p} \hat{\alpha} \hat{\alpha}^{\prime} S_{p o}=S_{o o}-\hat{\beta} \hat{\beta}^{\prime}
\end{array}\right.
$$

The $r$ cointegrating vectors are provided by the $r$ most significant eigenvectors, i.e., the $r$ eigenvectors which correspond to the $r$ largest eigenvalues solutions of the equation: $\left|\lambda S_{p p}-S_{p o} S_{o o}^{-1} S_{p o}\right|=0$

To find the value of $r$ (i.e., the number of cointegrating vectors) Johansen proposed to use two statistics:

$$
\begin{aligned}
& \lambda_{\text {trace }}=T R=-T \sum_{i=q+1}^{N} \log \left(1-\hat{\lambda}_{i}\right) \\
& V P_{\text {max }}=-T \log \left(1-\hat{\lambda}_{q+1}\right)
\end{aligned}
$$


$\lambda_{\text {trace }}$ tests null hypothesis: that is, there are at most $r$ cointegrating vectors. This test amounts to testing the rank of the matrix $\pi_{p}$ i.e., we test $H_{0}: R g\left(\pi_{p}\right)=r$

Johansen (1988) showed that under $H_{0}$ the statistic trace has for asymptotic law of:

$\int_{0}^{1} W(r) d W^{\prime}(r)\left(\int_{0}^{1} W(r) W^{\prime}(r) d r\right)^{-1} \int_{0}^{1} d W(r) d W^{\prime}(r)$

Where $W$ is a Brownian motion of the variance-covariance matrix the identity matrix. The critical values of the $\lambda_{\text {trace }}$ Statistics have been tabulated by Johansen and Juseluis (1990) then by Osterwald-Lenum (1992). We reject the null hypothesis of $r$ cointegrating relations when the statistic $\lambda_{\text {trace }}$ trace is greater than its critical value.

Theories of cointegration allow specifying stable long-term relationships while jointly analyzing the short-term dynamics of the variables considered. This requires the use of a particular class of models directly related to cointegration: VECM. Consequently, VEC modeling and cointegration give a new dimension to dynamic modeling by providing it with solid theoretical bases and by making it possible to consistently identify the longterm properties of time series.

With cointegration transformation of formula (3), we can get that:

$\Delta Y_{t}=\Pi y_{t-1}+\sum_{i=1}^{p-1} \Gamma_{i} \Delta y_{t-1}+u_{t}$

Where $\Pi=\sum_{i=1}^{p} A_{i}-I$,

$$
\Gamma_{i}=-\sum_{j=i+1}^{p} A_{j}
$$

If $Y_{t}$ has a cointegration relationship, then $\Pi y_{t-1} \sim \mathrm{I}(0)$ and formula (28) can be written as follows:

$\Delta Y_{t}=\alpha \hat{\beta} y_{t-1}+\sum_{i=1}^{p-1} \Gamma_{i} \Delta y_{t-i}+u_{t}$

Where, $\dot{\beta} y_{t-1}=e c m_{t-1}$ is the error correction term, which reflects the long-term equilibrium relationships between variables. Equation (14) comes:

$\Delta Y_{t}=\alpha e c m_{t-1}+\sum_{i=1}^{p-1} \Gamma_{i} \Delta y_{t-i}+u_{t}$

Formula (15) is the vector error correction model (VECM), in which each equation is an error correction model.

\section{Results and Discussion}

3.1 Unit root tests application (ADF, PP, KPSS).

The analysis of chronological/times series is primarily concerned with examining their stationary nature by presenting the various tests used in this context. When studying time series, we need to test for the presence of a unit root to demonstrate whether or not a chronicle is stationary and to determine the correct way of stationary. The Dickey and Fuller tests (DF and ADF) are the most widely used due to their great simplicity, but they also suffer from several criticisms which have led to the development of other unit root tests including those by Phillips and Perron (PP) (1988), Kwiatkowski, Phillips, Schmidt, and Shin (KPSS) (1988) which we present in table 1. Table1: Unit root tests on variables

\begin{tabular}{|c|c|c|c|c|c|c|c|}
\hline Variables & \multicolumn{2}{|c|}{ At level } & \multicolumn{3}{|c|}{ At first Difference } & \multicolumn{2}{|c|}{ Conclusion } \\
\hline & $\mathrm{ADF}$ & PP & $\mathrm{ADF}$ & PP & KPSS & & \\
\hline $\mathrm{Ln}(\mathrm{CO2})$ & -1.5055 & -1.5161 & 0.1632 & $-6.0138 * * *$ & $-6.0185 * *$ & $0.0795 *$ & I (1) \\
\hline $\operatorname{Ln}(\mathbf{A L})$ & -2.2444 & -2.3341 & 0.0924 & $-5.7704 * *$ & $-6.5570 * *$ & $0.1444 * *$ & I (1) \\
\hline $\operatorname{Ln}(E U)$ & -1.4898 & -1.3111 & 0.1762 & $-7.5507 * * *$ & $-7.5851 * * *$ & $0.0973 * * *$ & I (1) \\
\hline Ln(AGRIF) & -1.4917 & -1.4917 & 0.1975 & $-3.8916 * *$ & $-3.8173 * *$ & $0.0679 * * *$ & I (1) \\
\hline $\operatorname{Ln}(G D P C)$ & -2.3362 & -2.2111 & 0.1979 & $-3.4963 *$ & $-3.4440 *$ & $0.0928 * * *$ & I (1) \\
\hline $\operatorname{Ln}($ INDCO) & -2.6044 & -2.5583 & 0.1957 & $-4.5181 * * *$ & $-4.4609 * * *$ & $0.1038 * * *$ & I (1) \\
\hline
\end{tabular}

Notes: (*) Significant at the 10\%; (**) Significant at the 5\%; (***) Significant at the 1\%. and (no) Not Significant *MacKinnon (1996) one-sided p-values

KPSS: The test says the p-value is significant (with p-value $<0.05$ ) and hence, you can reject the null hypothesis (series is stationary) and derive that the series is NOT stationary.

Source: Author's calculations.

All series are non-stationary in their level at the various critical thresholds since all the calculated values are greater than those tabulated, which implies the rejection of the null hypothesis of stationarity. On the other hand, it is not stationary in the tendency to critical thresholds $1 \%, 5 \%$ and $10 \%$ since the test statistics are lower than the critical values so we accept the null hypothesis of stationarity. Based on all performed unit root tests statistics, it was concluded that most of the variables are non-stationary at their level but stationary after taking the first difference i.e., I (1) variables.

\subsection{Estimation of VAR Model.}

The presence of one or more cointegration relations, therefore, allows us to go further and estimate a certain error correction model allowing us to specify the short-term dynamics of the variables present to reach the stable equilibrium long term. 
The first step of this analysis consists of determining the number of lags of the VAR model (p). To do this, we estimate a certain number of autoregressive processes and we retain the one that jointly minimizes the criteria of Akaike and Schwartz. Table 2 shows all the results retained.

Table 2: Determination of Lag Length Criteria

\begin{tabular}{|c|c|c|c|c|c|c|}
\hline Lag & Log L & LR & FPE & AIC & SC & HQ \\
\hline 0 & 263.0797 & NA & $4.24 \mathrm{e}-15$ & -16.06748 & -15.79266 & -15.97639 \\
\hline 1 & 422.8284 & $249.607^{*}$ & $1.94 \mathrm{e}-18$ & -23.80177 & $-21.8779^{*}$ & $-23.1640^{*}$ \\
\hline 2 & 464.4242 & 49.39501 & $1.76 \mathrm{e}-18^{*}$ & $-24.1515^{*}$ & -20.57878 & -22.96725 \\
\hline
\end{tabular}

* indicates lag order selected by the criterion

LR: sequential modified LR test statistic (each test at 5\% level

FPE: Final prediction error

AIC: Akaike information criterion

SC: Schwarz information criterion

HQ: Hannan-Quinn information criterion

Source: Author's calculations.

\subsection{Johansen cointegration test (trace test)}

The trace test assumes the absence of the trend in the cointegrating relationship and the absence of the constant in the error correction model. This choice can be justified economically by assuming that the long-term equilibrium relationships do not contain a trend. We, therefore, test the cointegration link between $\mathrm{CO} 2$ emissions and the factors that influence it, according to our study, namely AL, EU, AGRIF, GDPC, and INDCO. We apply the test of Johansen $(1988)$ of the trace $\left(\chi_{\text {trace }}\right)$ and of the eigenvalue $\left(\chi_{\max }\right)$.

Table3: Johansen cointegration test results

\begin{tabular}{|c|c|c|c|c|c|c|}
\hline Ho: Rang r & Eigenvalue & $\chi_{\text {trace }}$ & $\begin{array}{c}\mathbf{0 . 0 5} \\
\text { Critical Value }\end{array}$ & Ho: Rang r & $\chi_{\text {tmax }}$ & $\begin{array}{c}\mathbf{0 . 0 5} \\
\text { Critical Value }\end{array}$ \\
\hline $\mathrm{r}=0 *$ & 0.768545 & 119.5026 & 95.75366 & $\mathrm{r}=0 *$ & 48.82787 & 40.07757 \\
\hline $\mathrm{r} \leq 1 *$ & 0.651531 & 72.67474 & 69.81889 & $\mathrm{r} \leq 1$ & 33.73456 & 33.87687 \\
\hline $\mathrm{r} \leq 2$ & 0.471245 & 38.94019 & 47.85613 & $\mathrm{r} \leq 2$ & 20.39138 & 27.58434 \\
\hline $\mathrm{r} \leq 3$ & 0.274117 & 18.54880 & 29.79707 & $\mathrm{r} \leq 3$ & 10.25172 & 21.13162 \\
\hline $\mathrm{r} \leq 4$ & 0.227945 & 8.297088 & 15.49471 & $\mathrm{r} \leq 4$ & 8.278368 & 14.26460 \\
\hline $\mathrm{r} \leq 5$ & 0.000585 & 0.018720 & 3.841466 & $\mathrm{r} \leq 5$ & 0.018720 & 3.8841466 \\
\hline
\end{tabular}

Trace test indicates 2 cointegrating equation(s) at the 0.05 level

* denotes rejection of the hypothesis at the 0.05 level

**MacKinnon-Haug-Michelis (1999) p-values

Source: Author's calculations.

The results of the Johansen test(table 3) show that the null hypothesis for the test of the trace $r=0$ and $r \leq 1$ for the test of the eigenvalue is rejected at the threshold of $5 \%$ since the values calculated from these two statistics (119.5026 and 72.67474). On the other hand, the null hypothesis for the test of the trace $r=0$ for the test of the maximum eigenvalue is rejected at the threshold of 5\% through the values calculated from that statistic (48.82787) is greater than the corresponding critical value. The null hypothesis $r \leq 1$ cannot be rejected at the $5 \%$ threshold since the two test statistics are lower than the critical values associated with them.

The following long-term equilibrium equation is retained:

$\operatorname{LnCO2}=2.558 \operatorname{Ln}(A L)_{t}-15.441 \operatorname{Ln}(E U)_{t}+1.504 \operatorname{Ln}(A G R I F)_{t}+6.178 \operatorname{Ln}(G D P C)_{t}-$

$$
5.671 \operatorname{Ln}(I N D C O)_{t}-5.671 \operatorname{Ln}(I N D C O)_{t}+139.8476
$$

This cointegration relation shows that environmental and economic variables AGRIF, AL have a positive long-term relationship with $\mathrm{CO} 2$ emissions respectively. If natural resource exploitation increases by $1 \%$, the environmental degradation which induces $\mathrm{CO} 2$ emissions follows the same trend with a percentage of $1.5 \%$ and $2.5 \%$ respectively. This cointegration goes hand in hand with the increase in income per habitat (GDPC) to ensure this relationship of cointegration. In favor of sustained energy consumption with a level of life more comfort, countries of sub-Saharan Africa highlight the decreasing carbon dioxide emissions. On the other hand, when energy consumption increases by $1 \%, \mathrm{CO} 2$ emissions in the region undergo a decrease of $15.44 \%$. Similarly, the increase in industries and constructions results in a decrease of 5.67\% $\mathrm{CO} 2$ emissions.

It is possible to estimate a vector error correction model(VECM). As its name indicates, it consists of correcting the estimation bias induced by cointegration. Since we have six variables, the VECM will have six equations presented in Table 4. 
Table 4. VECM estimation results and test

\begin{tabular}{|c|c|c|c|c|c|c|}
\hline Error Correction: & D(LNCO2) & D(LNAL) & D(LNEU) & D(LNAGRIF) & D(LNGDP) & D(LNINDCO) \\
\hline CointEq1 & -0.114910 & -0.031438 & -0.032473 & 0.230806 & 0.053379 & -0.033148 \\
\hline & {$[-2.28079]$} & {$[-1.41076]$} & {$[-2.12625]$} & {$[2.33440]$} & {$[0.56496]$} & {$[-0.25123]$} \\
\hline D(LNCO2(-1)) & 0.030630 & -0.017362 & 0.102600 & -0.246978 & -0.221675 & -0.196759 \\
\hline & {$[0.13285]$} & {$[-0.17025]$} & {$[1.46800]$} & {$[-0.54585]$} & {$[-0.51268]$} & {$[-0.32585]$} \\
\hline D(LNAL(-1)) & -0.322750 & -0.142696 & 0.018604 & 0.302737 & 0.186491 & 0.021580 \\
\hline & {$[-0.77306]$} & {$[-0.77274]$} & {$[0.14700]$} & {$[0.36950]$} & {$[0.23819]$} & {$[0.01974]$} \\
\hline D(LNEU(-1)) & 0.481608 & 0.189113 & -0.375866 & -1.291758 & -1.248027 & -0.638851 \\
\hline & {$[0.66725]$} & {$[0.59236]$} & {$[-1.71787]$} & {$[-0.91195]$} & {$[-0.92201]$} & {$[-0.33796]$} \\
\hline D(LNAGRIF(-1)) & 0.071891 & -0.056267 & 0.040488 & 0.174520 & 0.017394 & -0.246380 \\
\hline & {$[0.51901]$} & {$[-0.91839]$} & {$[0.96427]$} & {$[0.64202]$} & {$[0.06696]$} & {$[-0.67918]$} \\
\hline D(LNGDPC(-1)) & -0.335876 & -0.220699 & 0.006934 & 1.299179 & 1.802981 & 2.386397 \\
\hline & {$[-0.84996]$} & {$[-1.26267]$} & {$[0.05788]$} & {$[1.67527]$} & {$[2.43292]$} & {$[2.30587]$} \\
\hline D(LNINDCO(-1)) & 0.337634 & 0.247612 & 0.033978 & -0.931347 & -0.994235 & -1.229316 \\
\hline & {$[1.19089]$} & {$[1.97455]$} & {$[0.39536]$} & {$[-1.67392]$} & {$[-1.86996]$} & {$[-1.65563]$} \\
\hline C & 0.014732 & 0.007457 & -0.007775 & 0.054350 & 0.028213 & 0.061287 \\
\hline & {$[1.15319]$} & {$[1.31976]$} & {$[-2.00766]$} & {$[2.16783]$} & {$[1.17760]$} & {$[1.83178]$} \\
\hline R-squared & 0.223808 & 0.256853 & 0.385147 & 0.372406 & 0.452128 & 0.371843 \\
\hline Akaike AIC & -3.242267 & -4.873754 & -5.629429 & -1.893868 & -1.984684 & -1.316731 \\
\hline Schwarz SC & -2.875833 & -4.507320 & -5.262995 & -1.527434 & -1.618250 & -0.950297 \\
\hline
\end{tabular}

Source: Author's calculations.

The equation which represents the short-run adjustments is the following equation relating to the variable LnCO2.

$$
\begin{aligned}
\Delta \ln (C O 2)_{t}= & 0.0147-0.3227 \ln (A L)_{t-1}+0.4816 \ln (E U)_{t-1}+ \\
& 0.0718 \ln (A G R I F)_{t-1}-0.335 \ln (G D P C)_{t-1}+0.337 \ln (I N D C O)_{t-1}- \\
0.1149 \varepsilon_{t-1} \quad(17) &
\end{aligned}
$$

This correction is presented by the return force of 0.1149 which remains negative and significant especially since it is justified by a Student statistic of (2.28079) in absolute value at the 5\% threshold. Also, the parameter of the error correction term is negative and significant, thus confirming the existence of a long-term relationship between $\mathrm{CO} 2$ emissions and the indicators considered. The value of this parameter further indicates that in the short-term imbalance, the $\mathrm{CO} 2$ emission seems to return fairly quickly to its equilibrium path (the speed of convergence is estimated at nearly $11 \%$ ). In the same way, the cointegration equation which is the error correction term has been formulated and interpreted in the (16) equation. The VECM model is valid for these cointegrated variables.

This VECM analysis sheds light on the meaning of the relationship between variables in the long and shortterm but does not provide insight into the sense of reaction between these variables. To interpret the interrelationships between variables, we propose in the next section, to study the causality between them by using the impulse response functions and the forecast error decomposition.

\subsection{Impulse response function and variance decomposition}

We mainly focus on shock response functions and variance decompositions of forecast errors. These two instruments make it possible to synthesize the essence of the information contained in the dynamics of the estimated VAR system.

3.4.1 Impulse response function.

The impulse response function is used to perform shocks on the innovations of $\mathrm{CO} 2$ emissions at 10 years and to measure the influence of this shock on the whole system. First of all, the shock only affects the value of $\mathrm{CO} 2$ emissions on the orthogonality innovations. Then, throughout the dynamics of the system, this shock is transmitted to the following or future values of all variables.

Figure $1[\mathrm{ABCDE}]$ retrace the impulse response functions. We consider that the amplitude of the shock is equal to twice the standard deviation and we are interested in the effects of the shock over 10 periods (i.e. 10 years). This horizon represents the time required for the variables to return to their long-term levels.

[A]After analysis of effects of $\mathrm{CO} 2$ emissions, the $\mathrm{CO} 2$ emissions decrease rapidly after a sensitive shock, reach the lowest point in the third period, then increase slowly, reach a peak average in the 5th period, and then decline again until the lowest point in the $6^{1 / 2}$ periode but return to a slow increase. This suggests that the positive shock of $\mathrm{CO} 2$ has a significant influence on its increasing, and the significant influence has relatively long sustained effectiveness.

$[\mathrm{B}]$ The results of different responses show that the response of $\mathrm{CO} 2$ emissions is characterized by a permanent 
negative shock. It's far diagnosed that agricultural land could have positive externalities which include the provision of environmental offerings and amenities, for instance via water storage and purification, carbon sequestration, and the preservation of rural landscapes(Fanelli 2020).

$[\mathrm{C}]$ The energy (EU) chock has, also, positive shocks(consequences) on $\mathrm{CO} 2$ emissions. The shock increase during the 4-5 period. Afterward, the energy shock to the $\mathrm{CO} 2$ emission continues to increase in the long run.

[D]The impulse response of CO2 emissions caused by agriculture, forestry, and fisheries (AGRIF) is characterized by a positive and transitory shock. As seen in the figure, the first positive shock in the first period causes a quick increase, and $\mathrm{CO} 2 \mathrm{emissions} \mathrm{reach} \mathrm{a} \mathrm{peak} \mathrm{in} \mathrm{the} \mathrm{second-period,} \mathrm{decrease} \mathrm{until} \mathrm{the} \mathrm{3rd} \mathrm{period,} \mathrm{and} \mathrm{then} \mathrm{remain} \mathrm{at} \mathrm{a}$ stable level. If the changing demand and use of land, watershed, and forestry are not managed through rigorous planning and zoning regulatory framework, impacts in real terms are escalated uncontrolled development, increased energy demand and emissions, inefficient transport systems, overburdened water, and sanitation systems leading to reduced livelihoods.

[F]The impulse response function of carbon emission changes caused by industrial-construction is permanent negative. After a positive shock in the first period, carbon emissions decline to the lowest point in the third period and begin to rise slowly. Then carbon emissions reach a peak in the fourth period, stay at a stable level, and slowly decrease in the 5th period. The $\mathrm{CO} 2$ emissions become stable from the eighth period. This shows that a positive shock on industrial-construction can cause changes in carbon emissions, and its effect becomes gentle since the eighth period.

[E]The impulse response function of carbon emission changes caused by the real gross domestic product shows negative permanent effects. The general decrease in greenhouse gas intensities with the increase in income follows a certain logic. When this standard of living increases, we observe that certain consumptions, in particular, those of first necessity increase at a rate lower than that of the income (Engel low).
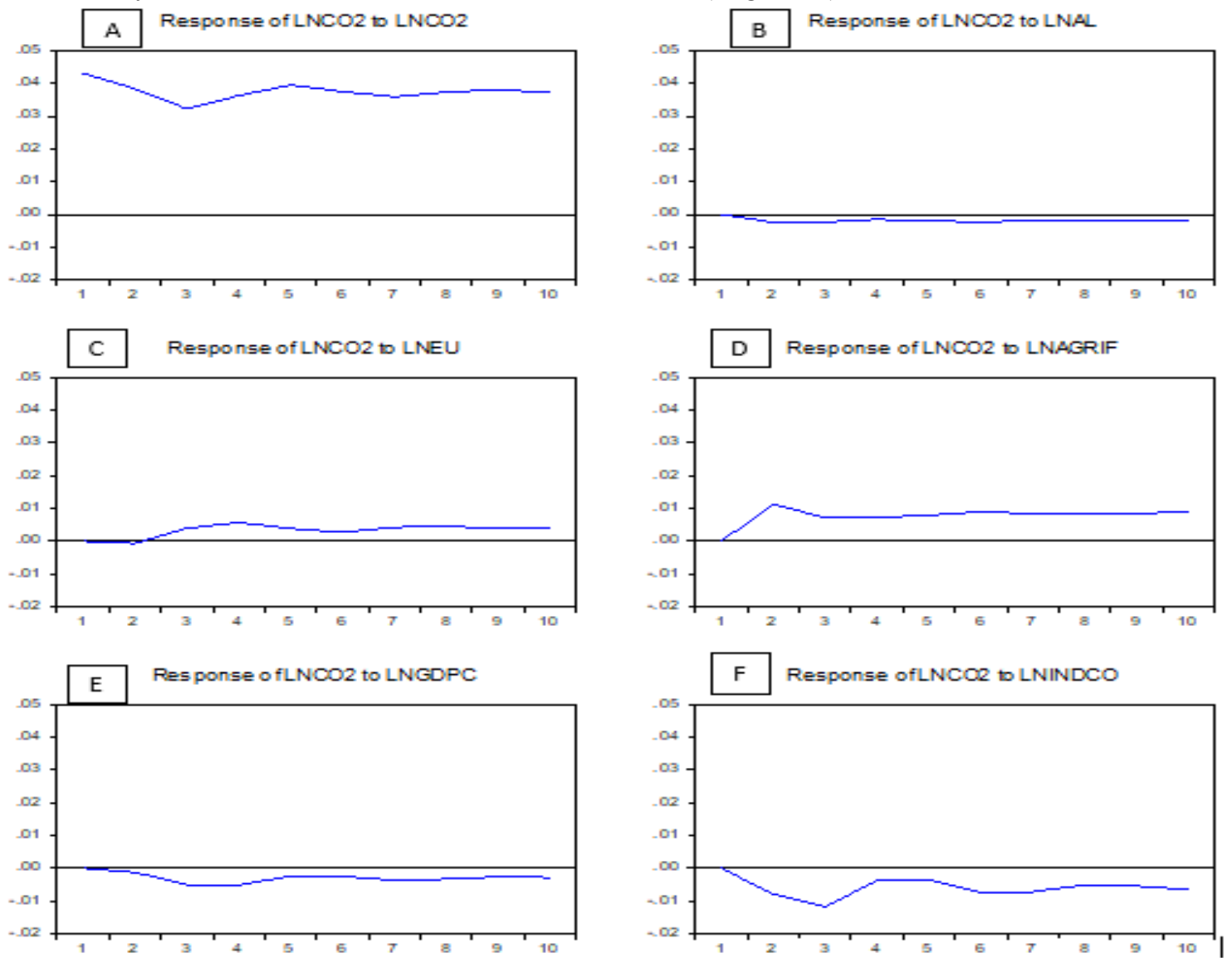

Figure 1. Response to Cholesky One S.D. Innovations

3.4.2 Variance Decomposition

This study, based on impulse response functions, can be supplemented by an analysis of the variance decomposition of the forecast error. The objective is to calculate the contribution of each of the innovations to the variance of the error. We write the variance of the forecast error at a horizon $h$, in our case ranging from 1 to 10 , depending on the variance of the error attributed to each of the six variables. 
Table5: Variance decomposition of LNCO2

\begin{tabular}{|c|c|c|c|c|c|c|c|}
\hline Period & S.E. & LNCO2 & LNAL & LNEU & LNAGRIF & LNGDPC & LNINDCO \\
\hline 1 & 0.043014 & 100.0000 & 0.000000 & 0.000000 & 0.000000 & 0.000000 & 0.000000 \\
\hline 2 & 0.059296 & 94.31938 & 0.172261 & 0.013527 & 3.676613 & 0.045819 & 1.772404 \\
\hline 3 & 0.069206 & 90.88376 & 0.249033 & 0.340410 & 3.756450 & 0.577961 & 4.192382 \\
\hline 4 & 0.078935 & 90.95158 & 0.230025 & 0.787427 & 3.718781 & 0.865278 & 3.446909 \\
\hline 5 & 0.088808 & 91.56881 & 0.238105 & 0.810875 & 3.744965 & 0.759410 & 2.877832 \\
\hline 6 & 0.097181 & 91.30279 & 0.251750 & 0.757541 & 3.986103 & 0.702072 & 2.999741 \\
\hline 7 & 0.104352 & 91.00204 & 0.258264 & 0.827080 & 4.108069 & 0.732813 & 3.071736 \\
\hline 8 & 0.111406 & 91.06544 & 0.257091 & 0.892215 & 4.146289 & 0.731805 & 2.907164 \\
\hline 9 & 0.118248 & 91.13347 & 0.259037 & 0.897652 & 4.213505 & 0.699646 & 2.796695 \\
\hline 10 & 0.124549 & 91.06317 & 0.262315 & 0.900827 & 4.294904 & 0.681767 & 2.797015 \\
\hline
\end{tabular}

Source: Author's calculation.

The variance decomposition results [table 5] made it possible to deduce that the variance of the $\mathrm{CO} 2$ forecast error is due for $91.06 \%$, over the 10 years horizon, to its innovations. It is largely due to $4.29 \%, 2.79 \%, 0.90 \%$, and $0.68 \%$ of agriculture, forestry, and fisheries, industrial construction, and energy use respectively.

\section{Conclusion}

The study empirically analyzes the impact of human activities on CO2 emissions in the Sub -Sahara African region by taking into account the stationary or non-stationary character of the data series. It was possible to estimate a vector error correction model (VECM) but the light on the meaning of the relationship between variables in the long and short-term did not provide insight into the sense of reaction between variables. We proposed then to study the causality between variables using the impulse response functions and the forecast error decomposition.

In the context of this work, it is important to summarize the main results:

The application of unit root tests revealed that all series are non-stationary in level but are integrated of the same order at their difference I (1). This has led to suspecting a possible long-term relationship (cointegration) between $\mathrm{CO} 2$ emissions and its explanatory variables.

Application of the Johansen cointegration test on variables found the existence of a long-term relationship between them. The output cointegration relation shows that environmental and economic variables agriculture, forestry, and fishing(value-added), Agricultural Land, and real Income have a positive long-term relationship with $\mathrm{CO} 2$ emissions. On the other hand, when energy consumption increases, $\mathrm{CO} 2$ emissions in the region undergo a decrease. Similarly, the increase in industry-construction results in a decrease in CO2emissions.

Through the impulse response function analysis, results of different responses showed that the impulse response of $\mathrm{CO} 2$ emissions changes caused by agricultural land, industry-construction, and the real gross domestic product is characterized by a permanent negative shock. Good agricultural land management gives a healthy environment that provides resources for habitats and further leads to the decline of carbon emissions. The rise in agriculture, forestry, and fisheries (AGRIF), and energy (EU) has, besides, positive shocks(consequences) on CO2 emissions. This shows that the growth of carbon emissions in the SSA does not necessarily promote AL, INDCO, and RGDP growth, and the growth of those sectors in the country does not intensify the excessive pollutants to cause plenty of carbon emissions.

In the long- term, the agriculture, forestry, and fisheries sector, industry-construction, and energy use have a great influence on CO2emissions but the influence is leveling off in the short run. To prevent any kind of loss linked to atmospheric pollution, a massive investment in clean energies (wind, geothermal, solar...) and biofuels should make it possible to prevent $\mathrm{CO} 2$ emissions in the long term. As for forests and agriculture, stopping deforestation of tropical forests, launching of reforestation projects, reform of agricultural practices to protect soils. This sector has a strong potential for reducing emissions because forests and soils constitute sinks of natural carbon.

\section{Declaration of competing interest}

No conflict of interest

\section{Funding}

Not applicable

\section{Author's Contribution}

Jean Baptiste helped with topic conceptualization and writing the initial draft. All authors contributed to the research implementation, discussion of results and we both approve for manuscript publication. 
Acknowledgment

Not applicable

\section{References}

Abeydeera, L. H. U. W., Mesthrige, J. W. and Samarasinghalage, T. I. (2019) 'Global research on carbon emissions: A scientometric review', Sustainability (Switzerland), 11(14), pp. 1-25. doi: 10.3390/su11143972.

Alam, J. (2015) 'Impact of Agriculture, Industry and Service Sector's Value Added in the GDP on CO2 Emissions of Selected South Asian Countries', World Review of Business Research, 5(2), pp. 39-59.

Ameyaw, B. and Yao, L. (2018) 'Analyzing the impact of GDP on CO2 emissions and forecasting Africa's total CO2 emissions with non-assumption driven bidirectional long short-term memory', Sustainability (Switzerland), 10(9). doi: 10.3390/su10093110.

Bär, R. et al. (2021) 'The future of charcoal, firewood, and biogas in Kitui County and Kilimanjaro Region: Scenario development for policy support', Energy Policy, 150(January). doi: 10.1016/j.enpol.2020.112067.

Blimpo, M. P. and Cosgrove-Davies, M. (2019) Electricity Access in Sub-Saharan Africa: Uptake, Reliability, and Complementary Factors for Economic Impact, Electricity Access in Sub-Saharan Africa: Uptake, Reliability, and Complementary Factors for Economic Impact. doi: 10.1596/978-1-4648-1361-0.

Bush, E. et al. (2018) 'Understanding Observed Global Climate Change', Canada's Changing Climate Report, pp. 24-72.

Engo, J. (2019) 'Decomposition of Cameroon's CO2 emissions from 2007 to 2014: an extended Kaya identity', Environmental Science and Pollution Research, 26(16), pp. 16695-16707. doi: 10.1007/s11356-019-05042$\mathrm{Z}$.

Eurostat (2015) 'Agriculture - greenhouse gas emission statistics', Eurostat Statistics Explained, (February 2021), pp. 1-8. Available at: https://ec.europa.eu/eurostat/statistics-explained/pdfscache/30599.pdf.

Fanelli, R. M. (2020) 'The spatial and temporal variability of the effects of agricultural practices on the environment', Environments - MDPI, 7(4), pp. 1-18. doi: 10.3390/environments 7040033.

Frantál, B., Pasqualetti, M. J. and van Der Horst, D. (2014) 'New trends and challenges for energy geographies: Introduction to the special issue', Moravian Geographical Reports, 22(2), pp. 2-6. doi: 10.2478/mgr-20140006.

Ganda, F. and Ngwakwe, C. C. (2014) 'Problems of sustainable energy in sub-Saharan Africa and possible solutions', Mediterranean Journal of Social Sciences, 5(6 SPEC. ISSUE), pp. 453-463. doi: 10.5901/mjss.2014.v5n6p453.

Hanck, C. et al. (2018) 'Introduction to econometrics with R', p. 400

Howes, M. et al. (2007) 'Environmental Sustainability : A Case of Policy Implementation Failure ?', pp. 1-17. doi: $10.3390 / \mathrm{su} 9020165$.

Hummels, H. and Argyrou, A. (2021) 'Planetary demands: Redefining sustainable development and sustainable entrepreneurship', Journal of Cleaner Production, 278, p. 123804. doi: 10.1016/j.jclepro.2020.123804.

Intergovernmental Panel on Climate Change and Intergovernmental Panel on Climate Change (2015) 'Agriculture, Forestry and Other Land Use (AFOLU)’, Climate Change 2014 Mitigation of Climate Change, pp. 811-922. doi: $10.1017 / \mathrm{cbo} 9781107415416.017$.

International Energy Agency (IEA) (2019) 'CO2 emisions from fuel combustion', IEA Publications, pp. 1-165. Available at: https://iea.blob.core.windows.net/assets/eb3b2e8d-28e0-47fd-a8ba160f7ed42bc3/CO2_Emissions_from_Fuel_Combustion_2019_Highlights.pdf.

Larmie, S. (2019) 'Savannah Investment Programme ( SIP ) ENVIRONMENTAL AND SOCIAL MANAGEMENT FRAMEWORK ( ESMF )'.

Leng, L. Y., Ahmed, O. H. and Jalloh, M. B. (2019) 'Brief review on climate change and tropical peatlands', Geoscience Frontiers, 10(2), pp. 373-380. doi: 10.1016/j.gsf.2017.12.018.

Levine, A. S. and Kline, R. (2017) 'A new approach for evaluating climate change communication', Climatic Change, 142(1-2), pp. 301-309. doi: 10.1007/s10584-017-1952-x.

Manfred Hafner, Simone Tagliapietra and Lucia De Strasser (2018) Energy in Africa: Challenges and Opportunities, SpringerBriefs in Energy. Available at: https://link.springer.com/content/pdf/10.1007\%2F978-3-319-92219-5.pdf.

Manisalidis, I. et al. (2020) 'Environmental and Health Impacts of Air Pollution: A Review', Frontiers in Public Health, 8(February), pp. 1-13. doi: 10.3389/fpubh.2020.00014.

Masron, T. A. and Subramaniam, Y. (2019) 'Does Poverty Cause Environmental Degradation? Evidence from Developing Countries', Journal of Poverty, 23(1), pp. 44-64. doi: 10.1080/10875549.2018.1500969.

Max William Ssali et al. (2018) 'Impact of Economic Growth, Energy Use and Population Growth on Carbon Emissions in Sub-Sahara Africa', Journal of Environmental Science and Engineering B, 7(5), pp. $178-192$. doi: 10.17265/2162-5263/2018.05.002.

Mikhaylov, A. et al. (2020) 'Global climate change and greenhouse effect', Entrepreneurship and Sustainability 
Issues, 7(4), pp. 2897-2913. doi: 10.9770/jesi.2020.7.4(21).

Miller, D. C. et al. (2021) 'A global review of the impact of forest property rights interventions on poverty', Global Environmental Change, 66(December 2019), p. 102218. doi: 10.1016/j.gloenvcha.2020.102218.

Nangombe, S. S. et al. (2019) 'High-Temperature Extreme Events Over Africa Under 1.5 and $2{ }^{\circ} \mathrm{C}$ of Global Warming', Journal of Geophysical Research: Atmospheres, 124(8), pp. 4413-4428. doi: $10.1029 / 2018 J D 029747$.

Niang, I. et al. (2015) 'Africa', Climate Change 2014: Impacts, Adaptation and Vulnerability: Part B: Regional Aspects: Working Group II Contribution to the Fifth Assessment Report of the Intergovernmental Panel on Climate Change, pp. 1199-1266. doi: 10.1017/CBO9781107415386.002.

Omisore, A. G. (2018) 'Attaining Sustainable Development Goals in sub-Saharan Africa; The need to address environmental challenges', Environmental Development, 25(September 2017), pp. 138-145. doi: 10.1016/j.envdev.2017.09.002.

Palmer, P. I. et al. (2019) 'Net carbon emissions from African biosphere dominate pan-tropical atmospheric CO2 signal', Nature Communications, 10(1), pp. 1-9. doi: 10.1038/s41467-019-11097-w.

Pant, K. P. (2009) 'Effects of Agriculture on Climate Change: A Cross Country Study of Factors Affecting Carbon Emissions', Journal of Agriculture and Environment, 10(August 2009), pp. 84-102. doi: 10.3126/aej.v10i0.2134.

Sarkodie, S. A. and Owusu, P. A. (2017) 'The relationship between carbon dioxide, crop and food production index in Ghana: By estimating the long-run elasticities and variance decomposition', Environmental Engineering Research, 22(2), pp. 193-202. doi: 10.4491/eer.2016.135.

Serdeczny, O. et al. (2017) 'Climate change impacts in Sub-Saharan Africa: from physical changes to their social repercussions', Regional Environmental Change, 17(6), pp. 1585-1600. doi: 10.1007/s10113-015-0910-2.

Shishaye, H. A. (2017) 'The Negative Impacts of Climate Change in Sub-Saharan Africa and their The Negative Impacts of Climate Change in Sub-Saharan Africa and their Mitigation Measures', (August). doi: 10.9734/BJAST/2015/17665.

Society, T. R. (2021) Climate change and global warming: Impacts on crop production, Genetically Modified Plants. doi: 10.1016/b978-0-12-818564-3.09991-1.

Solomon, S., Qin, D. and Manning, M. (2007) 'How do Human Activities Contribute to Climate Change and How do They Compare with Natural Influences?', The Physical Science Basis. Available at: https://www.ipcc.unibe.ch/publications/wg1-ar4/faq/docs/AR4WG1_FAQ-Brochure_LoRes.pdf.

Sperry, J. S. et al. (2019) 'The impact of rising CO2 and acclimation on the response of US forests to global warming', Proceedings of the National Academy of Sciences of the United States of America, 116(51), pp. 25734-25744. doi: 10.1073/pnas.1913072116.

Wang, C. S. H. and Hafner, C. M. (2018) 'A simple solution of the spurious regression problem', Studies in Nonlinear Dynamics and Econometrics, 22(3), pp. 1-14. doi: 10.1515/snde-2015-0040.

Wickham, J. et al. (2019) 'EPA Public Access', Advances in Ecological Research, 60, pp. 1-24. doi: 10.1039/c7pp90001e.Environmental.

Xing, X. et al. (2019) 'How energy consumption and pollutant emissions affect the disparity of public health in countries with high fossil energy consumption', International Journal of Environmental Research and Public Health, 16(23). doi: 10.3390/ijerph16234678.

Yorganc1, B. (2018) 'No 主観的健康感を中心とした在宅高齢者における 健康関連指標に関する共分散構 造 分 析 Title', Gastrointestinal Endoscopy, 10(1), pp. 279-288. Available at: http://dx.doi.org/10.1053/j.gastro.2014.05.023\%0Ahttps://doi.org/10.1016/j.gie.2018.04.013\%0Ahttp://ww w.ncbi.nlm.nih.gov/pubmed/29451164\%0Ahttp://www.pubmedcentral.nih.gov/articlerender.fcgi?artid=PM C5838726\%250Ahttp://dx.doi.org/10.1016/j.gie.2013.07.022.

Zhang, H. et al. (2020) 'Dynamic analysis of agricultural carbon emissions efficiency in Chinese provinces along the Belt and Road', PLoS ONE, 15(2), pp. 1-22. doi: 10.1371/journal.pone.0228223.

Zhao, X., Gerety, M. and Kuminoff, N. V. (2018) 'Revisiting the temperature-economic growth relationship using global subnational data', Journal of Environmental Management, 223(June), pp. 537-544. doi: 10.1016/j.jenvman.2018.06.022. 